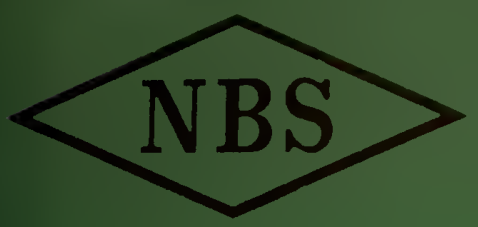

Eechnical Note No.208

\title{
CALCULATED DIFFRACTION EFFECTS AT VLF FROM A LOCALIZED IONOSPHERIC DEPRESSION
}

JAMES R. WAII

U. S. DEPARTMENT OF COMMERCE NATIONAL BUREAU OF STANDARDS 


\section{THE NATIONAL BUREAU OF STANDARDS}

\section{Functions and Activities}

The functions of the National Bureau of Standards include the development and maintenance of the national standards of measurement and the provision of means and methods for making measure ments consistent with these standards; the determination of physical constants and properties of materials: the development of methods and instruments for testing materials, devices, and structures; advisory services to government agencies on scientific and technical problems; invention and development of devices to serve special needs of the Government; and the development of standard practices, codes, and specifications, including assistance to industry, business and consumers in the development and acceptance of commercial standards and simplified trade practice recommendations. The work includes basic and applied research, development, engineering, instrumentation, testing, evaluation, calibration services, and various consultation and information services. Research projects are also performed for other government agencies when the work relates to and supplements the basic program of the Bureau or when the Bureau's unique competence is re quired. The scope of activities is suggested by the listing of divisions and sections on the inside of the back cover.

\section{Publications}

The results of the Bureau's research are published either in the Bureau's own series of publications or in the journals of professional and scientific societies. The Bureau itself publishes three periodicals available from the Government Printing Office: The Journal of Research, published in four separate sections, presents complete scientific and technical papers; the Technical Vews Bulletin presents sunmary and preliminary reports on work in progress; and Central Radio Propagation Laboratory Ionospheric Predictions provides datafor determining the best frequencies to use for radio communications throughout the world. There are also seven series of nonperiodical publications: Monographs, Applied Mathematics Series, Handbooks, Miscellaneous Publications, Technical Notes, Commercial Standards, and Simplified Practice Recommendations.

A complete listing of the Bureau's publications can be found in National Bureau of Standards Circular 460, Publications of the National Bureau of Standards, 1901 to June $1947(\$ 1.25)$, and the Supplement to National Bureau of Standards Circular 460, July 1947 to June 1957 (\$1.50), and Miscellaneous Publication 240, July 1957 to June 1960 (includes Titles of Papers Published in Outside Journals 1950 to 1959) (\$2.25); available from the Superintendent of Documents, Government Printing Office, Washington, D.C., 20402. 


\title{
NATIONAL BUREAU OF STANDARDS \\ Eechnical Note 208 \\ Issued January 16, 1964
}

\section{CALCULATED DIFFRACTION EFFECTS \\ AT VLF| FROM A LOCALIZED \\ IONOSPHERIC DEPRESSION}

\author{
James R. Wait \\ Central Radio Propagation Laboratory \\ National Bureau of Standards \\ Boulder, Colorado
}

NBS Technical Notes are designed to supplement the Bureau's regular publications program. They provide a means for making available scientific data that are of transient or limited interest. Technical Notes may be listed or referred to in the open literature. 



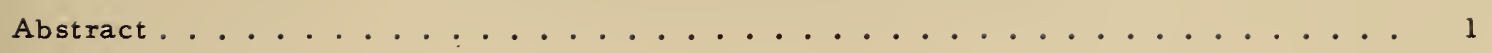

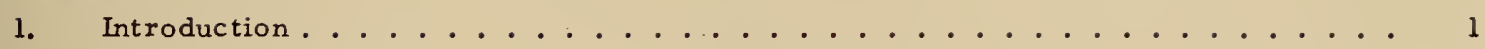

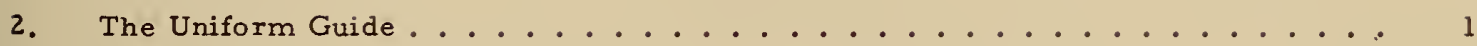

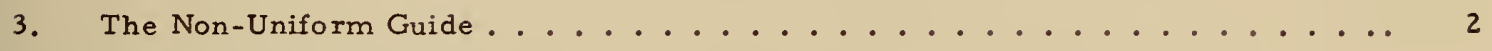

4. Some Concrete Results ........................... 5

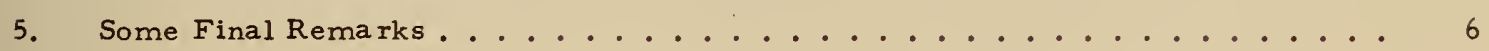

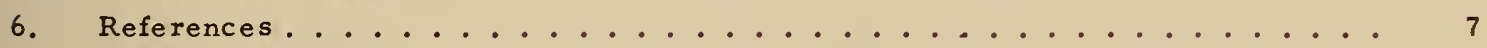

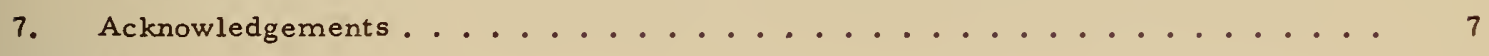

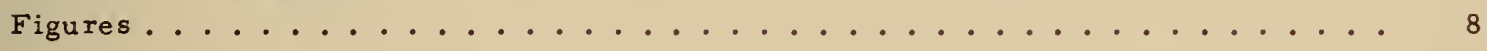





\title{
CALCULATED DIFFRACTION EFFECTS AT VLF FROM A LOCALIZED IONOSPHERIC DEPRESSION ${ }^{\dagger}$
}

\author{
James R. Wait
}

\begin{abstract}
Propagation of VLF radio waves in the earth-ionosphere waveguide of non-uniform width is considered. The disturbed region is permitted to be of finite extent. It is assumed that the height variations may be locally represented in terms of a propagation function $S(x, y)$ which is a function of both $x$ and $y$. Using first-order scattering theory, calculations are presented for a disturbed region which is approximately rectangular in the horizontal plane.
\end{abstract}

\section{Introduction}

It is now becoming recognized that the propagation of VLF radio waves is influenced by ionospheric disturbances which occur along all or part of the great circle path between transmitter and receiver. However, it is not always appreciated that ionospheric perturbation lying off the great circle path may also have a significant effect. A quantitative estimate of these off-great-circle disturbances is of particular importance in connection with the detection of nuclear detonations. It is known that the $\mathrm{x}$-ray radiation resulting from the explosion will produce additional ionization at $\mathrm{D}$ - and E-region heights of the ionosphere. In this note, the results of some calculations a re presented which bear on this important problem. The detailed derivation of the required equations were given earlier /Wait, 1963]; however, for purposes of completeness, a brief discussion of the plausibility of the working formulas is given here.

\section{The Uniform Guide}

In order to achieve tractability, without becoming encumbered in details, some simplifying assumptions are made at this juncture. It is assumed that the space between the earth, of radius a, and the ionosphere is equivalent to a waveguide which supports only several modes of low attenuation. In fact, for distances of the order of $4000 \mathrm{~km}$ or greater, it is necessary to consider only one mode for frequencies of the order of $20 \mathrm{kc} / \mathrm{s}$. Thus, at a distance d from the transmitting antenna, the vertical electric field $E$ is given approximately by [Wait, 1962]

$$
E \cong \frac{\text { const. }}{[\sin (d / a)]^{\frac{1}{2}}} \exp \left(-i k d S_{1}\right)
$$

$†$

The resealch reported here was supported by the Advanced Research Projects Agency under ARPA Order No. 183-62. 
if the height $h$ and properties of the ionosphere did not vary. Here, $k=2 \pi /$ wavelength, and thus $\mathrm{kS}_{1}$ is the (complex) propagation constant of the dominant mode. For example, the phase velocity is $\left(c / \operatorname{Re} S_{1}\right)$ where $c$ is the velocity of light and the attenuation rate is $\left(-k \operatorname{Im} S_{1}\right)$ nepers per unit length. In what follows, the subscript 1 on $\mathrm{S}$ is dropped.

\section{The Non-Uniform Guide}

In a first approach in treating the influence of variable ionospheric heights, one generalizes equation (1) to allow for the dependence of $\mathrm{S}$ on the distance $\mathrm{x}$, along the great circle, from the transmitting antenna. Thus, [Wait, 1961]

$$
E \cong \frac{\text { const. }}{[\sin (d / a)]^{\frac{1}{2}}} \exp \left(-i k \int_{0}^{d} S(x) d x\right) \text {. }
$$

As indicated previously, this is a valid representation for an earth-ionosphere waveguide whose width varies slowly along the great circle path. Obviously, such a simple formula ignores variations in the transverse or $y$ direction. In particular, if the perturbed region lies off the great circle path, the above formula for $E$ would give no information concerning the corresponding modification to the field.

A somewhat heuristic approach to the general problem is based on the concept that the integral in the exponent of equation (2) is the resultant of the individual contributions from the whole $x, y$ plane. $S(x, y)$, which is regarded as a function of both $x$ and $y$, will contribute to the modification of the field whenever it departs significantly from the undisturbed constant value $S^{\circ}$. This suggests, with a certain amount of hindsight, that the field under disturbed conditions should have the form

$$
E=E^{0} \exp \left(-i k \int_{-x_{0}}^{x_{1}} \Omega(x) d x\right)
$$

where $E^{\circ}$ is the field under undisturbed conditions and $\Omega(x)$ is a function of $x$, yet to be determined. Here, the coordinates of the transmitter and receiver are $\left(-x_{0}, 0\right)$ and $\left(x_{1}, 0\right)$, respectively. In view of the remarks made above, $\Omega(x)$ must involve an integral over the transverse direction y. Also, the integrand must be weighted by $S(x, y)-S^{\circ}$ which is the "local contrast" and furthermore, account must be taken of the different electrical lengths of the paths connecting transmitte $r$ and receiver. After some consideration, it is found that [Wait, 1963]

$$
\Omega(\mathrm{x})=\left(\frac{\mathrm{i}}{\pi}\right)^{\frac{1}{2}} a \int_{\mathrm{y}_{1}(\mathrm{x})}^{\mathrm{y}_{2}(\mathrm{x})}\left[\mathrm{S}(\mathrm{x}, \mathrm{y})-\mathrm{S}^{\circ}\right] \exp \left(-\mathrm{i} a^{2} \mathrm{y}^{2}\right) \mathrm{dy},
$$

where the $y$ integration extends over the interval $y_{1}$ to $y_{2}$ which encompasses the ionospheric perturbations. In this equation

$$
a^{2}=\frac{k S^{0}}{2}\left[\frac{\left(x_{1}-x_{0}\right)}{\left(x_{0}-x\right)\left(x_{1}+x\right)}\right] \text {. }
$$


As shown before, [Wait, 1963] in a full analytical treatment of this problem, the factor -i $a^{2} y^{?}$ is the correction for the phase which retains only second-order terms in $y$. Also, it should be mentioned that the form for $a$, given above, is strictly valid only on a flat earth. However, earth curvature changes this factor by only a small amount, and for present purposes, this correction is ignored.

It is immediately evident, from the form of equation (4), that if $S(x, y)$ is independent of $y$ and if $\left(-y_{1}\right)$ and $\left(+y_{2}\right)$ are sufficiently large,

$$
\begin{aligned}
\Omega(x) & \cong\left(\frac{i}{\pi}\right)^{\frac{1}{2}} a \int_{-\infty}^{+\infty}\left[S(x, 0)-S^{0}\right] \exp \left(-i a^{2} y^{2}\right) d y \\
& \cong S(x, 0)-S^{0} .
\end{aligned}
$$

Inserting this value into equation (3) gives the required form of the modified field $E_{\infty}$ when the ionospheric disturbance is effectively infinite in the transverse direction.

In order to present numerical data in a convenient form, it is desirable to normalize the results to the ionospheric depression which has an infinite transverse direction. For example, the E field, under disturbed conditions, may be written

$$
\frac{E}{E^{0}} \cong \exp \left[-i k \int_{-\delta / 2}^{\delta / 2} \Omega(x) d x\right]
$$

where $E^{\circ}$ is the corresponding field for an undisturbed ionosphere and $\delta$ is the range of $x$ which encompasses the perturbation. Now, if the function $S(x, y)-S^{\circ}$ is independent of $y$, it follows that

$$
\frac{E}{E^{0}}=\frac{E_{\infty}}{E^{0}}=\exp \left[-i k \int_{-\delta / 2}^{\delta / 2}\left[S(x)-S^{0}\right] d x\right] \text {. }
$$

The "normalized field anomaly" NFA may then be defined by the ratio

$$
\frac{\log \left(E / E^{\circ}\right)}{\log \left(E_{\infty} / E^{\circ}\right)}=N F A \text {. }
$$

It is obvious that NFA approaches one when the perturbation has an infinite transverse dimension. Thus, a quantitative evaluation of NFA gives a good index of the effectiveness of an ionospheric disturbance of finite width.

For purposes of illustration, $S(x, y)$ and $S^{\circ}$ may be regarded as real. (In actual fact, they have small imaginary parts.) Furthermore, it is assumed that $S(x, y)$ differs from $S^{\circ}$ only over a rectangular region bounded by $y_{1}<y<y_{2}$ and $-\delta / 2<x<\delta / 2$ as indicated in figure 1 . 


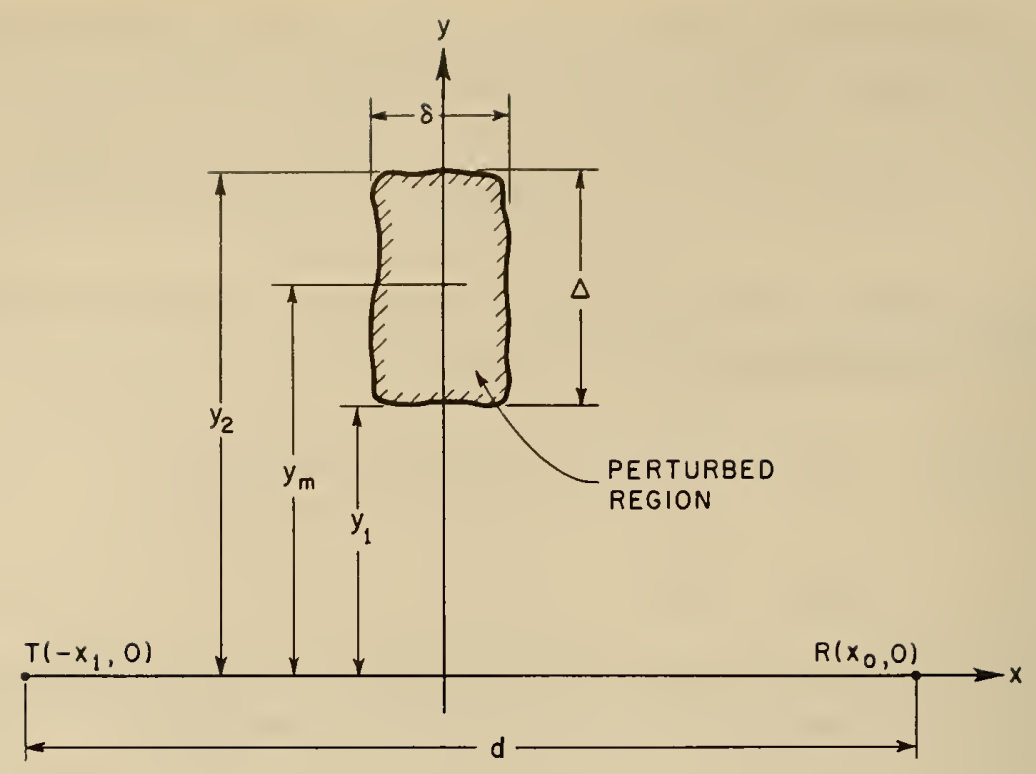

FIGURE 1 - PLAN VIEW OF SIMPLE IONOSPHERIC PERTURBATION SHOWING LOCATIONS OF TRANSMITTING AND RECEIVING ANTENNAS (SCALE EXAGGERATED IN y DIRECTION)

Also, in order to achieve more simplicity, it is assumed that the difference or contrast function $S(x, y)-S^{\circ}$ is constant over this rectangular region. It is then found that

$$
\frac{\log \left(E / E^{0}\right)}{\log \left(E_{\infty} / E^{0}\right)}=N F A \cong\left[\frac{1}{1-i} \int_{Z_{1}}^{Z_{2}} e^{-i(\pi / 2) t^{2}} d t\right] \text {, }
$$

where

$(\pi / 2)^{\frac{1}{2}} z_{1}=a y_{1}$,

and

$(\pi / 2)^{\frac{1}{2}} \mathrm{z}_{2}=a \mathrm{y}_{2}$,

with

$$
a \cong\left(\frac{\mathrm{k}}{2}\right)^{\frac{1}{2}}\left(\frac{\mathrm{x}_{1}+\mathrm{x}_{0}}{\mathrm{x}_{0} \mathrm{x}_{1}}\right)^{\frac{1}{2}} \text {. }
$$


In obtaining equation (10), it has also been assumed that $x_{0}$ and $x_{1}>>$, and $S^{\circ}$ is replaced by unity.

\section{Some Concrete Results}

The normalized field anomaly NFA, as defined above, is a complex quantity. Its real part may be defined as the normalized phase anomaly, NPA, while the imaginary part is defined as the normalized amplitude anomaly, NAA. Specifically,

$$
N P A=\frac{1}{2}\left[C\left(z_{2}\right)-C\left(z_{1}\right)+s\left(z_{2}\right)-s\left(z_{1}\right)\right] \text {, }
$$

and

$$
N A A=\frac{1}{2}\left[S\left(z_{2}\right)-S\left(z_{1}\right)-C\left(z_{2}\right)+C\left(z_{1}\right)\right]
$$

where

$$
C(Z)=\int_{0}^{Z} \cos \left(\frac{\pi}{2} t^{2}\right) d t,(13) \text { and } S(Z)=\int_{0}^{Z} \sin \left(\frac{\pi}{2} t^{2}\right) d t
$$

are Fresnel integrals [Born and Wolf, 1959].

The quantity NPA is a measure of the modification of the phase of signal ratio $\mathrm{E} / \mathrm{E}^{\circ}$. One should note that

$$
\log E / E^{\circ}=\log \left|E / E^{\circ}\right|+i \arg \left(E / E^{\circ}\right),
$$

while

$$
\log E / E_{\infty}^{0}=i \arg \left(E_{\infty} / E^{0}\right)
$$

since $\left|E / E^{\circ}\right|$ is essentially unity when the imaginary part of $S(x)$ is neglected. Thus

$$
N P A \cong \frac{\arg \left(E / E^{\circ}\right)}{\arg \left(E_{\infty} / E^{\circ}\right)}
$$

and

$$
N A A \cong-\frac{\log \left|E / E^{\circ}\right|}{\arg \left(E_{\infty} / E^{\circ}\right)} \cong \frac{1-\left|E / E^{\circ}\right|}{\arg \left(E_{\infty} / E^{\circ}\right)}
$$

To show numerical calculations, the following special case is considered; namely, $x_{0}=x_{1}=d / 2$, which states that the perturbed region is equidistant from the two ends of the path. Also, the frequency is taken to be $20 \mathrm{kc} / \mathrm{s}$, corresponding to a wavelength, $\lambda=15 \mathrm{~km}$.

In figure 2, NPA and NAA are shown plotted as a function of $y_{1}$ for the case where $\mathrm{y}_{2}-\mathrm{y}_{1}=\Delta \rightarrow \infty$ and $\mathrm{d}=\mathrm{x}_{0}+\mathrm{x}_{1}=4000 \mathrm{~km}$. It is noted that NPA asymptotically approaches unity for $y_{1}$ sufficiently negative. This limit corresponds to an ionospheric perturbation which is effectly infinite in the transverse direction. Then, as $y_{1}$ is increased, in the positive direction, NPA oscillates and at $y_{1}=0$ it becomes exactly $1 / 2$. Furtherincreases of $y_{1}$ reduce NPA until it asymptotically approaches zero. The latter limit corresponds to removing the ionospheric perturbation an "infinite "distance off the path. 
It is interesting to note that the normalized amplitude anomaly, NAA, oscillates about zero with maximum excursions when $y_{1}$ is in the vicinity of 0 . Within the approximation that $S(x, y)$ is real, conservation of energy demands that the average value of NAA, with respect to $y_{1}$, is zero.

The curves of NPA and NAA shown in figure 3 are for the same conditions as those in figure 2 except that $d=10,000 \mathrm{~km}$. Qualitatively, the results are very similar. The main difference is that the period of the oscillations and the transition region is stretched out in the transverse direction.

Results of somewhat greater practical interest are shown in figure 4 where NPA is plotted as a function of $y_{m}=y_{1}+(\Delta / 2)$ for various values of $\Delta$ the width of the perturbed region. (See figure 1 for relevant geometry.) The wavelength is $15 \mathrm{~km}$ and the total range $\mathrm{d}$ is $4000 \mathrm{~km}$. These curves are even about $\mathrm{y}_{\mathrm{m}}=0$, so only positive values are shown in the abscissa. Also, in order to conserve space, the ordinates are shifted by 0.5 for each curve.

As expected, the curves in figure 4 show that NPA asymptotically approaches zero for values of $y_{m}$ while it becomes approximately unity when $y_{m}$ is near zero. Because of the interference from various diffracted waves, the structure of the field variations are rather complex although there is some semblance of a periodicity at larger values of $\mathrm{y}_{\mathrm{m}}$.

Curves in figure 5 are for the same conditions as for figure 4 except that now $\mathrm{d}=10,000 \mathrm{~km}$. The expected stretching of the abscissa is evident along with other changes in detail.

A set of curves showing NAA for $d=4000 \mathrm{~km}$ and $10,000 \mathrm{~km}$ are given in figures 6 and 7 , respectively. These are for the same conditions as the corresponding NPA curves in figures 4 and 5. The NAA curves in figures 6 and 7 are even about $y_{m}=0$, and at the same time, the average value of NAA is zero with respect to $\mathrm{y}_{\mathrm{m}}$.

\section{Some Final Remarks}

While the results in figures. 2 to 7 inclusive are for a wavelength of $15 \mathrm{~km}$, the results may be simply scaled to other wavelengths if corresponding changes are made in the other parameters. For example, in a microwave model of this situation, $\lambda$ might be $3.0 \mathrm{~cm}$. leading to a scale factor $\mathrm{p}=15 \mathrm{~km} / 3 \mathrm{~cm}=5 \times 10^{5}$. All other dimensions must then be divided by $\mathrm{p}$ if the diffraction patterns are to be invariant. For example, in figure 5, the total distance $d=20$ meters and the 4 values of $\Delta$, reading from top to bottom, are $20 \mathrm{~cm}, 30 \mathrm{~cm}, 40 \mathrm{~cm}$, and $60 \mathrm{~cm}$.

The correction for earth curvature has been implicitly neglected in all the above discussion. The principal modification is to change the horizontal scale in figures 2 to 7 inclusive. It is not difficult to show that the numerical values of $y_{1}$ or $y_{m}$ should be multiplied by the factor $x$ where

$$
X=\frac{\tan (d / 2 a)}{(d / 2 a)}
$$

and $a$ is the radius of the earth. For example, this amounts to an increase of about 2 percent and 12 percent, respectively, for $\mathrm{d}=4000 \mathrm{~km}$ and $\mathrm{d}=10,000 \mathrm{~km}$, respectively. Actually, $\mathrm{X}$ is equal 
to the ratio of the width of a Fresnel zone on a spherical earth to that on a flat earth. It is important to note that in a convenient microwave model such as a parallel plate waveguide, $X$ would be unity and yet it may be used to determine diffraction effects when $X$ is not unity.

The results given in this note, although based on relatively simple theoretical concepts, should give some insight into the behavior of the earth-ionosphere waveguide of non-uniform width. Some of the methods used in this work bear a certain resemblance to an analysis carried out recently by Crombie [1963] who argues from the viewpoint of physical optics. His final results appear to agree with the formulas derived by the author [Wait, 1963] using analytical methods, and his conclusions are compatible with the numerical data given here.

\section{References}

Born, M. , and E. Wolf (1959): Principles of optics (Pergamon Press, Oxford).

Crombie, D.D. (1963), On the effects of a small local ionospheric height depression on the propagation of a VLF radio signal (to be submitted to J. Res. NBS, Sec. D).

Wait, J.R. (Oct. 1961). Expected influence of a localized change of ionospheric height on VLF propagation, J. Geophys. Res. 66, No. 10, 3119-3123.

Wait, J.R. (1962). Electromagnetic Waves in Stratified Media (Pergamon Press, Oxford).

Wait, J.R. (Oct. 1963), On phase changes in VLF propagation induced by an ionospheric depression of finite extent, ARPA Project Report (to be published).

\section{Acknowledgements}

I would like to thank Mrs. Carolen M. Jackson and Mrs. Lillie C. Walters for programming the Fresnel integrals, Tom Griffiths for drafting the illustrations, and Mrs. Eileen A. Brackett for assistance in preparing the manuscript. I would also like to thank D.D. Crombie and A. G. Jean for some useful discussions of this subject. 


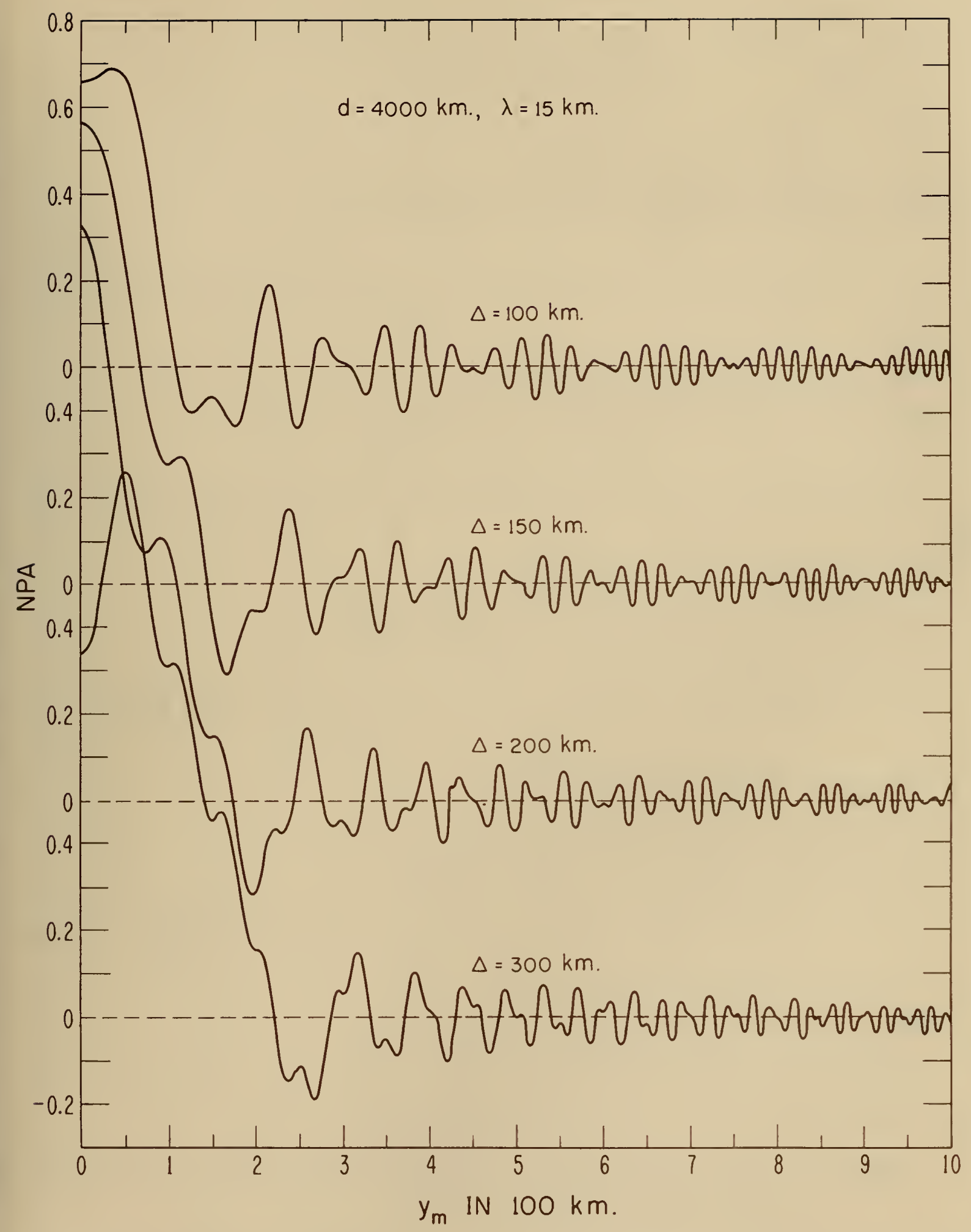

FIGURE 4 - NPA AS A FUNCTION OF $y_{m}$ MEASURED TO THE CENTER OF A RECTANGULAR SHAPE DEPRESSION FOR $d=4000 \mathrm{KM}$ 


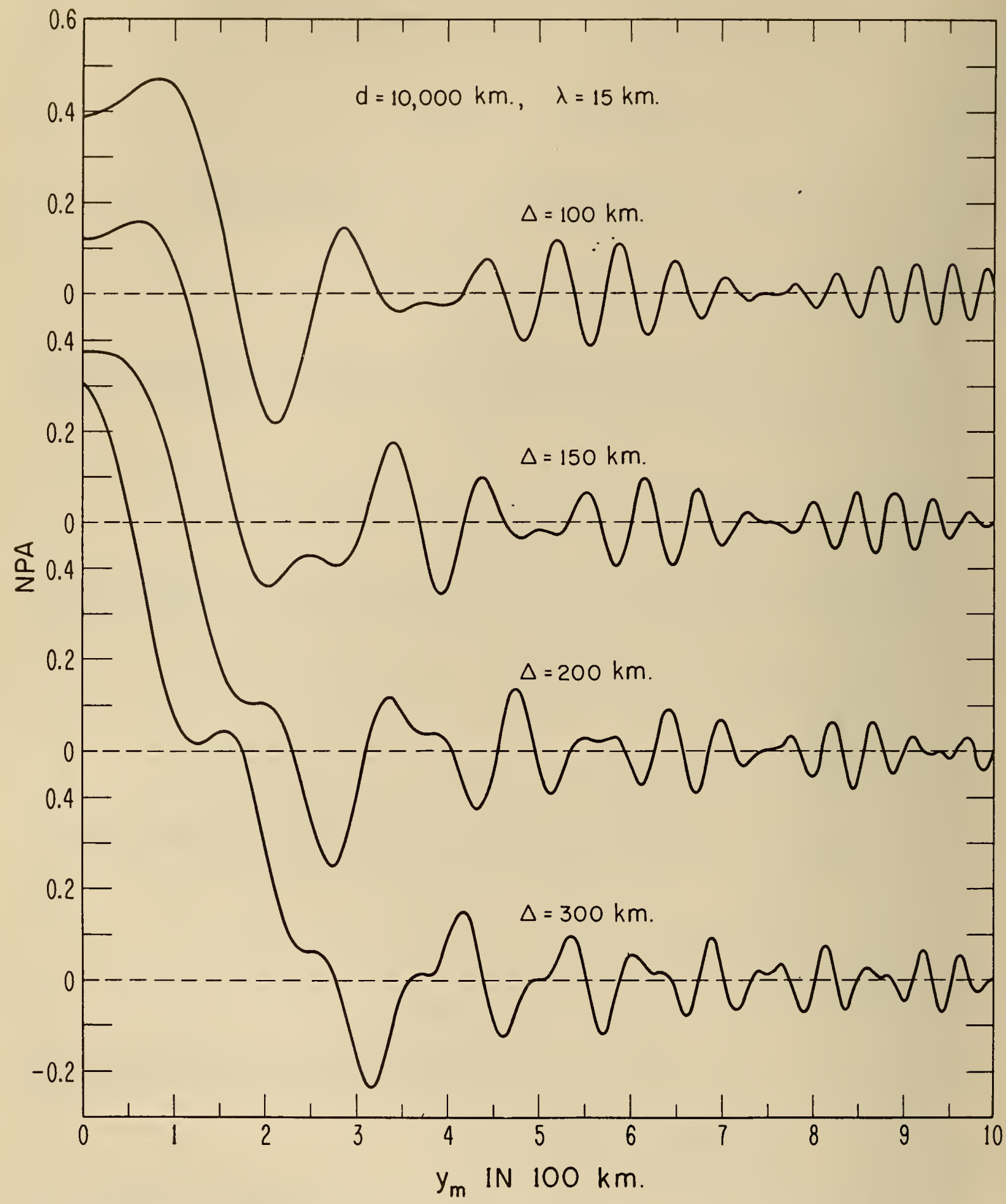

FIGURE 5 - NPA AS A FUNCTION OF $y_{m}$ MEASURED TO THE CENTER OF A RECTANGULAR SHAPE DEPRESSION FOR $d=10,000 \mathrm{KM}$ 


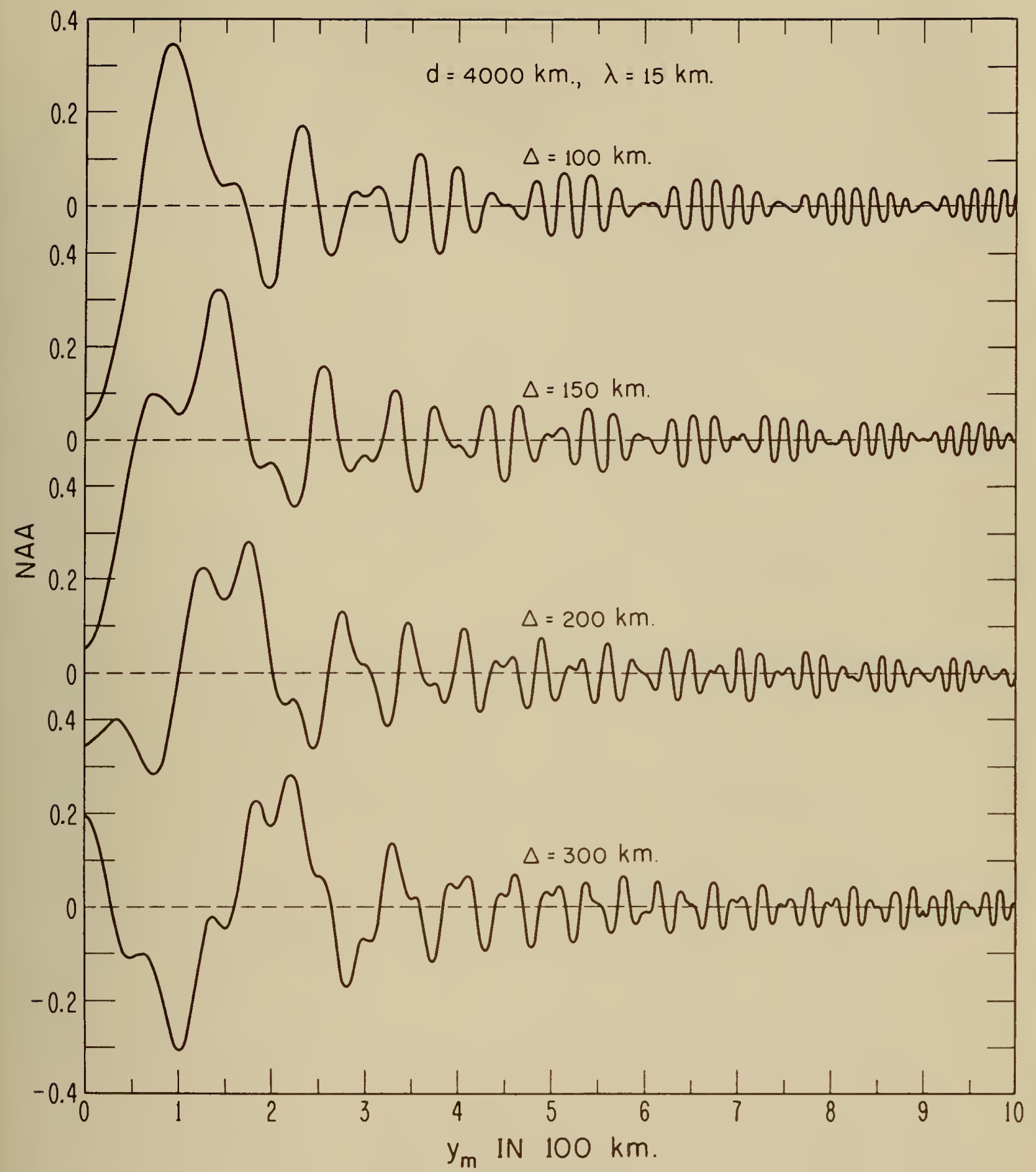

FIGURE 6 - NAA AS A FUNCTION OF $y_{m}$ MEASURED TO THE CENTER OF A RECTANGULAR SHAPE DEPRESSION FOR $d=4000 \mathrm{KM}$ 


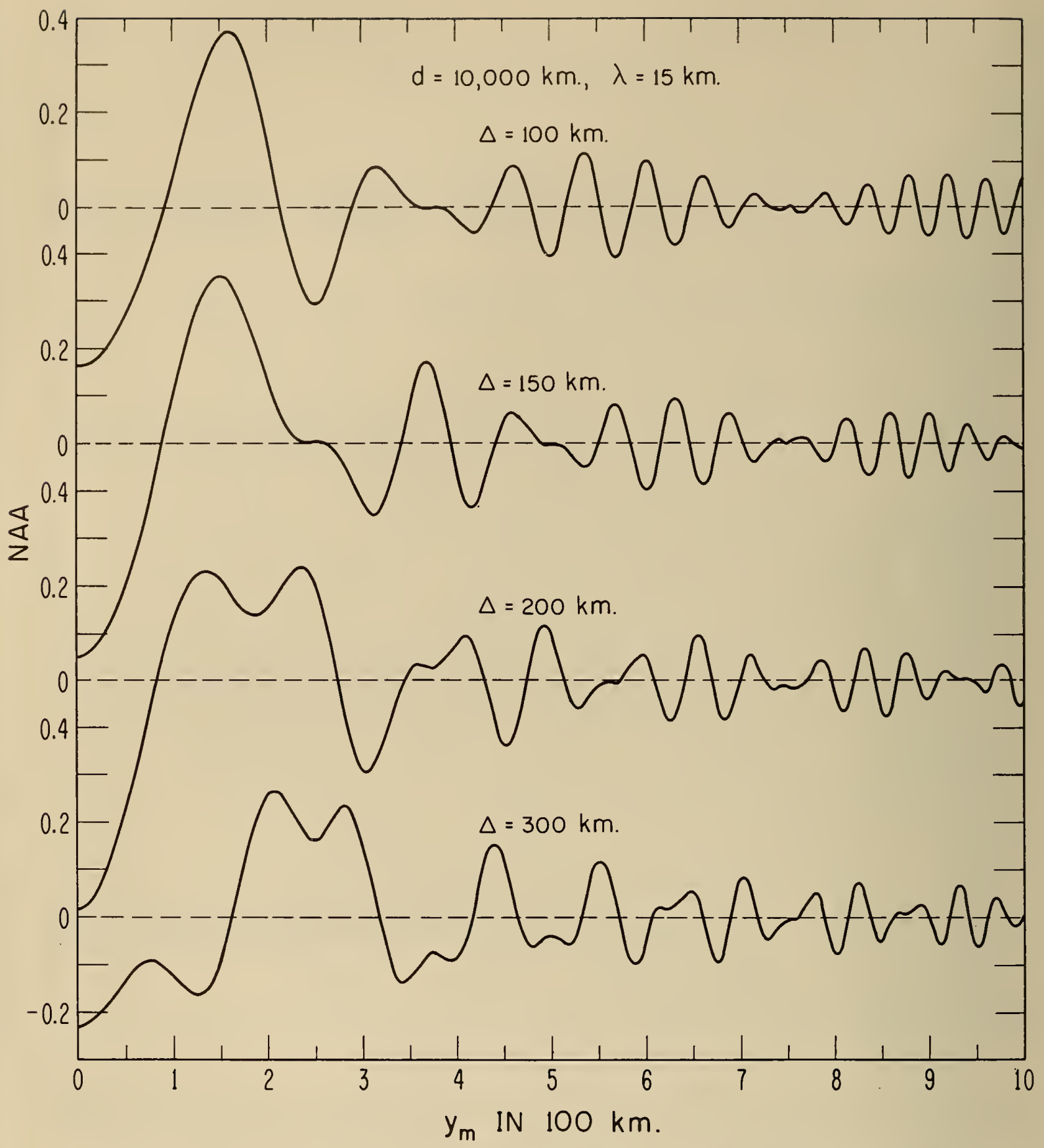

FIGURE 7 - NAA AS A FUNCTION OF $y_{m}$ MEASURED TO THE CENTER OF A RECTANGULAR SHAPE DEPRESSION FOR $d=10,000 \mathrm{KM}$ 
The scope of activities of the National Bureau of Standards at its majo: laboratories in Hashington, D.C., and Boulder, Colorado, is suggested in the following listing of the divisions and sections engaged in technical work. In general, each section carries out specialized research, development, and engineering in the field indicated by its title. A brief description of the activities, and of the resultant publications, appears on the inside of the front cover.

\section{WASIIINGTON, D. C.}

Electricity. Resistance and Reactance. Electrochemistry. Electrical lnstruments. Magnetic Measurements. Dielectrics. High Voltage. Absolute Electrical Measurements.

Metrology. Photometry and Colorimetry. Refractometry. Photographic Research. Length. Engineering Mletrology. Mass and Volume.

Heat. Temperature Physics. Heat Measurements. Cryogenic Physics. Equation of State. Statistical Physics. Radiation Physics. X-ray. Radioactivity. Radiation Theory. High Energy Radiation. Radiological Equipment. Nucleonic Instrumentation. Neutron Physics.

Analytical and Inorganic Chemistry. Pure Substances. Spectrochemistry. Solution Chemistry. Standard Reference Materials. Applied Analytical Research. Crystal Chemistry.

Mechanics. Sound. Pressure and Vacuum. Fluid Mechanics. Engineering Mechanics. Rheology. Combustion Controls.

Polymers. Macromolecules: Synthesis and Structure. Polymer Chemistry. Polymer Physics. Polymer Characterization. Polymer Evaluation and Testing. Applied Polymer Standards and Research. Dental Research.

Metallurgy. Engineering Metallurgy. Metal Reactions. Metal Physics. Electrolysis and Metal Deposition. Inorganic Solids. Engineering Ceramics. Glass. Solid State Chemistry. Crystal Growth. Physical Properties. Crystallography.

Building Research. Structural Engineering. Fire Research. Mechanical Systems. Organic Building Materıals. Codes and Safety Standards. Heat Transfer. Inorganic Building Mlaterials. Metallic Building Materials.

Applied Mathematics. Numerical Analysis. Computation. Statistical Engineering. Mathematical Physics. Operations Research.

Data Processing Systems. Components and Techniques. Computer Technology. Measurements Automation. Engineering Applications. Systems Analysis.

Atomic Physics. Spectroscopy. Infrared Spectroscopy. Far Ultraviolet Physics. Solid State Physics. Flectron Physics. Atomic Physics. Plasma Spectroscopy.

Instrumentation. Engineering Electronics. Electron Devices. Electronic Instrumentation. Mechanical lnstruments. Basic Instrumentation.

Physical Chemistry. Thermochemistry. Surface Chemistry. Organic Chemistry. Molecular Spectroscopy. Elementary Processes. Mass Spectrometry. Photochemistry and Radiation Chemistry.

Office of Weights and Measures.

BOLLDEK, COLO.

\section{CRYOGENIC ENGINEERING LABORATORY}

Cryogenic Processes. Cryogenic Properties of Solids. Cryogenic Technical Services. Properties of Cryogenic Fluids.

\section{CENTRAL RADIO PROPAGATION LABORATORY}

Ionosphere Research and Propagation. Low Frequency and Very Low Frequency Research. lonosphere Research. Prediction Services. Sun-Earth Relationships. Field Engineering. Radio Rarning Services. Vertical Soundings Research.

Troposphere and Space Telecommunications. Data Heduction Instrumentation. Radio Noise. Tropospheric Measurements. Tropospheric Analysis. Spectrum I'tilization Research. Radio-Mleteorologv. Lower Atmosphere Physics.

Radio Systems. Applied Electromagnetic Theory. High Frequency and Very High Frequency Research. Frequency Utilization. Modulation Research. Antenna Rescarch. Radiodetermination.

Upper Atmosphere and Space Physics. Upper Atmosphere and Plasma Physics. High Latitude lonosphere Physics. Ionosphere and Exosphere Scatter. Airglow and Aurora. lonospheric Radio Astronomy.

\section{RADIO STANDARDS LABORATORY}

Radio Standards Physics. Frequency and Time Disseminations. Radio and Microwave Materials. Atomic Fre quency and Time-Interval Standards. Radio Plasma. Microwave Physics.

Radio Standards Engineering. High Frequency Electrical Standards. High Frequency Calibration Services. High Frequency lmpedance Standards. Microwave Calibration Services. Microwave Circuit Standards. Low Frequency Calibration Services.

Joint Institute for Laboratory Astrophysics-NBS Group (L'niv. of Colo.). 


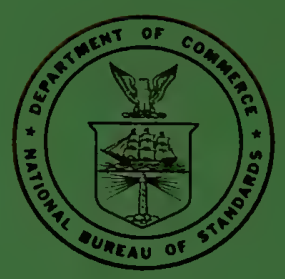

